\title{
Whey fermented by using Lactobacillus plantarum strains: A promising approach to increase the shelf life of pita bread
}

\author{
L. Izzo, ${ }^{1 *} \dagger$ † C. Luz, ${ }^{2} \dagger$ A. Ritieni, ${ }^{1}$ ㄴ J. Mañes, ${ }^{2}$ and G. Meca ${ }^{2}$ \\ ${ }^{1}$ Department of Pharmacy, University of Naples "Federico II," Via Domenico Montesano 49, 80131 Napoli, Italy \\ ${ }^{2}$ Laboratory of Food Chemistry and Toxicology, Faculty of Pharmacy, University of Valencia, Av. Vicent Andrés Estellés s/n, 46100 Burjassot, \\ Spain
}

\section{ABSTRACT}

Nowadays, there is an increasing concern regarding the shelf life of food products, leading producers to research natural antimicrobial agents to use in food preparation. In this study, we evaluated the antifungal activity of Lactobacillus plantarum fermented whey and then added the whey during preparation of pita bread to study shelf-life improvement. The fermented whey showed a satisfactory inhibitory (antifungal) effect against Penicillium expansum and Penicillium brevicompactum strains: the minimum inhibitory and minimum fungicidal concentrations ranged from 3.9 to $39.0 \mathrm{~g} / \mathrm{L}$ and from 62.5 to $250 \mathrm{~g} / \mathrm{L}$, respectively. Addition of fermented whey increased the shelf life of the pita bread. After inoculation of the bread surface with Penicillium, an increase in shelf life until d 8 was achieved compared with the positive control, whereas under natural contamination conditions, an extension of shelf life until d 19 was observed. In terms of antimicrobial activity, the greatest reduction (100\%) in fungal growth was achieved when all of the water in the dough was replaced with fermented whey. An untrained sensory panel could not identify differences between bread produced with fermented whey and control pita breads. These results suggest the possibility of using fermented whey in food preservation.

Key words: whey, shelf life, pita bread, antifungal activity, Penicillium strains

\section{INTRODUCTION}

Food waste is an important global issue in food security; 89 million tonnes of food is wasted per year (approximately one-third of the total food produced for human consumption), and it is expected to increase by up to $40 \%$ in 2020 . Food loss caused by food deteriora-

Received September 5, 2019.

Accepted February 28, 2020.

*Corresponding author: luana.izzo@unina.it

$\dagger$ These authors contributed equally to this work. tion occurs in the entire food system, but the most concerning is the loss of fruit and vegetable products (45\%), followed by cereal and bakery products (30\%), dairy products (20\%), and legumes (20\%; Gustavsson et al., 2011).

Bakery products represent an important source of nutrients consumed in a balanced diet. They are subjected to chemical, physical, and microbial spoilage that limit the shelf life of these products. Fungi belonging to the Penicillium, Aspergillus, Cladosporium, and Neurospora genera, particularly, Penicillium commune, Penicillium solitum, Penicillium corylophilum, and Aspergillus flavus are among the most common spoilage organisms found in baked products (Axel et al., 2017).

The stability of bakery products against natural spoilage and contamination by microorganisms is mainly due to preservatives. Without them, the shelf life of bread is around 3 to $4 \mathrm{~d}$ (Mondal and Datta, 2008; Saranraj and Geetha, 2012). European Commission Regulation 1333/2008/EC regulates the maximum content of food additives, such as propionic acid and propionate, to $3,000 \mathrm{mg} / \mathrm{kg}$ in prepacked sliced bread and rye bread; $2,000 \mathrm{mg} / \mathrm{kg}$ in energy-reduced bread, partially or prebaked bread, prepacked rolls, and buns; and $1,000 \mathrm{mg} / \mathrm{kg}$ in prepacked bread (European Commission, 2008; EFSA, 2016).

Given consumers' increasing concerns regarding synthetic additives in food preparation, there is a growing interest in researching and developing natural antimicrobial agents to inhibit the growth of fungi, the main agent responsible for food deterioration (Leyva Salas et al., 2017).

Whey has an estimated worldwide production at around 145 million tonnes, with a growth rate of 1 to $2 \%$ yearly (CLAL, 2016). Sweet whey is also used in whey dairy beverages, for producing ricotta and milk blends (Trindade et al., 2019). Of the total production, $59 \%$ is used in the industry (whey powder and lactose $58 \%$, whey protein concentrate and isolate $35 \%$, and the remaining $7 \%$ used for other industrial products) and $41 \%$ is disposed of as feed, fertilizer, or waste (Ganju and Gogate, 2017; Bacenetti et al., 2018). 
Due to its unique properties and chemical and physical characteristics, whey is an excellent candidate to release natural preservatives useful to delay microbial growth and reduce food waste (Jideani and Vogt, 2016; Ribes et al., 2018).

Even though intact whey proteins have several important biological activities, the hydrolysis of proteins through enzymes or during fermentation leads to the release of secondary metabolites and antimicrobial compounds associated with beneficial health effects (Dullius et al., 2018; Raveschot, et al., 2018). The use of lactic acid bacteria (LAB) as a starter culture to ferment food products and beverages has a long and safe history of application, dating back to the late 19th century (Leroy and De Vuyst, 2004).

Based on reported evidence, our objective was to evaluate the shelf life of pita bread prepared using fermented goat whey as a natural preservative. To achieve this, we first evaluated antifungal activity of whey fermented by different strains of LAB and then incorporated whey fermented by LAB in pita bread, in freeze-dried or liquid form, to prevent fungal growth.

\section{MATERIALS AND METHODS}

\section{Chemicals and Reagents}

Wheat flour, sugar, salt, instant yeast, and extra virgin olive oil were purchased in a shop market in Valencia, Spain. Deionized water $(<18 \mathrm{M} \Omega \cdot \mathrm{cm}$ resistivity) was obtained from a Milli-Q water purification system (Millipore, Bedford, MA). Buffered peptone water, potato dextrose agar (PDA), potato dextrose broth (PDB), and de Man, Rogosa, Sharpe medium (MRS) broth were provided by Oxoid (Madrid, Spain). Liquid sweet whey (LSW) supplied by the ALCLIPOR company, S. A. L. (Benassal, Spain) was made by the addition of commercial rennet (starter culture R-604 contained Lactococcus lactis ssp. cremoris and Lactococcus lactis ssp. lactis; Hansen Ltd., Cork, Ireland) to goat milk without chemical preservatives. Sweet whey is a dilute product with total solids of about $6.5 \%$ and composed of lactose $(4.5 \%)$, whey protein $(0.9 \%)$, ash $(0.7 \%)$, and fat $(0.4 \%)$. Whey was stored upon arrival at $4{ }^{\circ} \mathrm{C}$ until analysis was carried out within $2 \mathrm{~d}$. Pasteurization was performed by heating sweet whey in a water bath to $63^{\circ} \mathrm{C}$, maintaining that temperature for $30 \mathrm{~min}$ with continuous mixing, followed by rapid cooling according to standardized guidelines (Roth-Walter et al., 2008).

\section{Microorganisms and Culture Conditions}

Lactobacillus plantarum strains CECT 220, 221, 223, and 748 were obtained from Colección Espanola de
Cultivos Tipo (CECT, Valencia, Spain) and stored at $-80^{\circ} \mathrm{C}$ in $25 \%$ glycerol. Before use, the cultures were thawed in sterile conditions and activated in sterile MRS broth at $37^{\circ} \mathrm{C}$ for $48 \mathrm{~h}$.

Mycotoxigenic strains of Penicillium expansum CECT 2278 and Penicillium brevicompactum CECT 2316 were purchased from the CECT. All strains were maintained in PDA at room temperature $\left(25^{\circ} \mathrm{C}\right)$ until use. Penicillium species were previously cultured in PDB liquid medium following the manufacturer's specifications (27 $\mathrm{g}$ of product per $1 \mathrm{~L}$ of distilled water) and sterilization of the Selecta autoclave medium (Barcelona, Spain) at $121^{\circ} \mathrm{C}$ for $20 \mathrm{~min}$.

\section{Whey Fermentation}

Liquid sweet whey was fermented with 4 different strains of lactobacilli (L. plantarum CECT 220, 221, 223 , and 748 ) for $72 \mathrm{~h}$ at $37^{\circ} \mathrm{C}$. The suspension of each $\mathrm{LAB}$ at a concentration of $10^{8} \mathrm{cfu} / \mathrm{mL}$ was added to 40 $\mathrm{mL}$ of pasteurized whey under a sterile hood. After the 72-h fermentation, the whey was centrifuged at 3,100 $\times$ $g$ for $10 \mathrm{~min}$ at $15^{\circ} \mathrm{C}$ to remove bacteria (5810R centrifuge, Eppendorf, Hamburg, Germany). A portion was used for LSW and a portion lyophilized. The cell-free supernatant was filtered through a $0.22-\mu \mathrm{m}$ filter, added to $1 \mathrm{~m} M$ phenylmethanesulfonyl fluoride (PMSF) protease inhibitor, and lyophilized. The lyophilized whey was stored at $-80^{\circ} \mathrm{C}$ and used for further analysis, in testing antifungal activity and in pita bread making. Both liquid and lyophilized whey were used in the pita bread making. The fermentation of sweet whey by each L. plantarum strain was performed in triplicate.

\section{Antifungal Activity Test}

Antifungal activity of fermented whey was assessed by using the Kirby-Bauer test reported by Luz et al. (2018) with slight modifications. Antifungal activity against 2 fungal strains of the genus Penicillium was assessed after $72 \mathrm{~h}$ of fermentation time for whey. Briefly, $70 \mu \mathrm{L}$ of lyophilized sample $(0.5 \mathrm{~g} / \mathrm{L})$ solubilized in PDB was added to wells (5 mm diameter) cut in PDA, which was previously spread plated with $1 \times 10^{4}$ fungal spores and kept at $26^{\circ} \mathrm{C}$ for $3 \mathrm{~d}$. Following incubation, the inhibition zones were measured. Halos $\geq 8$ to $10 \mathrm{~mm}$ were considered positive for antifungal activity.

\section{Determination of MIC and Minimum Fungicidal Concentration}

A quantitative evaluation of the antifungal activity of fermented whey by L. plantarum strains was determined using the method of Puškárová et al. (2017) with 
some modifications. A negative control without the addition of spores and a positive control in the presence of spores were included. The assay was performed using a micro-dilution technique in 96-well sterile microplates to obtain serial dilution concentrations. First, $0.5 \mathrm{~g}$ of the lyophilized sample was resuspended in $1 \mathrm{~L}$ of PDB. We added $100 \mu \mathrm{L}$ of this sample to $100 \mu \mathrm{L}$ of spores at a concentration of $5 \times 10^{4}$ to obtain a final concentration range of 250 to $1.95 \mathrm{~g} / \mathrm{L}$. The 96 -well microplates were incubated at $26^{\circ} \mathrm{C}$ for $72 \mathrm{~h}$. The MIC is the lowest concentration of extract able to inhibit the visible growth of a microorganism. The minimum fungicidal concentration (MFC) is defined as the lowest concentration resulting in a $99.9 \%$ reduction in the starting inoculum. To determine MFC, $10 \mu \mathrm{L}$ of each concentration with visible fungal growth was seeded on PDA plates. The MFC value was determined after $72 \mathrm{~h}$ of incubation at $26^{\circ} \mathrm{C}$.

\section{Preparation of Pita Bread Dough, Inoculation, and Packaging}

Pita bread was prepared by adapting the method reported by Saladino et al. (2016) with slight modifications. Commercial wheat flour $(250 \mathrm{~g})$ was mixed with sugar $(2.5 \mathrm{~g})$, extra virgin olive oil $(20 \mathrm{~mL})$, salt $(5 \mathrm{~g})$, instant yeast $(15 \mathrm{~g})$, and the amount of water needed to reach the recommended compactness necessary to obtain good quality pita bread $(125 \mathrm{~mL})$. The dough was mixed for $12 \mathrm{~min}$ in the Simon extensometer mixer (model AM10, MBH, Barcelona, Spain) and left to rise for $30 \mathrm{~min}$ at $30^{\circ} \mathrm{C}$ in the dark. Then, the dough was divided into 40-g portions, rolled to the desired thickness of approximately 6 to $7 \mathrm{~mm}$ (4 $\mathrm{cm}$ in diameter), placed on a perforated greased plate, and baked at $180^{\circ} \mathrm{C}$ for $7 \mathrm{~min}$ in a muffle furnace (Memmert ULE 500 AO; Barloworld Scientific S.A., Madrid, Spain). After baking, pita bread samples were cooled to room temperature $\left(20-22^{\circ} \mathrm{C}, 1 \mathrm{~h}\right)$ and immediately prepared to be inoculated with Penicillium. Eight different types of pita bread were prepared: Pita bread without synthetic additives (positive control); pita bread with $0.2 \%$ calcium propionate (negative control); pita bread with $1 \%$ freeze-dried whey fermented by $L$. plantarum 220 (treatment 1), L. plantarum 221 (treatment 2), or L. plantarum 223 (treatment 3); pita bread prepared by replacing $100 \%$ of the water in the dough with liquid whey fermented by L. plantarum 220 (treatment 4); L. plantarum 221 (treatment 5); or L. plantarum 223 (treatment 6); in addition, the same treatments described above (8 types) were also prepared for pita bread produced without any artificial fungal contamination.
The antifungal activity of fermented whey was tested both in bread artificially contaminated with the chosen fungal spores ( $P$. expansum CECT 2278 and P. brevicompactum CECT 2316) and on bread exposed under natural contamination conditions. The efficacy of fermented whey to inhibit fungal growth on bread was evaluated following the method used by Ryan et al. (2011) with some modifications.

After baking, 9 replicas for each type of pita bread were inoculated in 9 spots with $100 \mu \mathrm{L}$ of a suspension containing $1 \times 10^{5}$ conidia $/ \mathrm{mL}$ of the chosen fungi and 9 replicas for each type allowed for natural contamination. Each 1 of the mentioned 9 replicas came from 3 distinct $(\mathrm{n}=3)$ fermentations with the same strain. Conidial concentration was measured by optical density at $600 \mathrm{~nm}$ and adjusted to $10^{8}$ conidia/mL in PDB as reported (Kelly et al., 2006). For the evaluation of inhibition of fungal growth in pita bread, $P$. expansum CECT 2278 and $P$. brevicompactum CECT 2316 were used. Finally, they were packed in sealed low-density polyethene bags using a Sammic TS-150 thermosealer (Basarte, Spain). All plastic bags were hermetically sealed and incubated at room temperature for 10 to 20 d. During this period, we checked the surface of the inoculated pita bread daily to identify growth or no growth of fungus and to establish the effect of treatments on shelf life.

\section{Antimicrobial Activity: Determination of Fungal Load}

Once the preservation period of pita bread samples was exceeded (i.e., 10 and $20 \mathrm{~d}$ for the artificially and naturally contaminated pita bread, respectively), we performed a microbiological study. Briefly, $10 \mathrm{~g}$ of each pita bread was homogenized with $90 \mathrm{~mL}$ of peptone water, previously autoclaved, in a Stomacher IUL (Barcelona, Spain) for $30 \mathrm{~s}$. From that mixture, 3 serial decimal dilutions were prepared in glass tubes with 9 $\mathrm{mL}$ of peptone water. Subsequently, $100 \mu \mathrm{L}$ from each tube was plated out in PDA culture medium plates. The plates were incubated at $26^{\circ} \mathrm{C}$, and the number of viable colonies counted after $72 \mathrm{~h}$ of incubation.

\section{Sensory Evaluation}

Sensory evaluation of the various types of pita bread was carried out using a 9-point hedonic scale as previously described by Samapundo et al. (2017). The scale ranged from dislike (1) to like extremely (9). The sensory evaluation of the pita bread was performed by 25 assessors, each of whom was presented with coded samples in random order and asked to evaluate the flavor of each sample in the order provided. Thirteen 
members of the panel (9 female and 4 male) were university members aged between 24 and 56 yr who had experience in tasting food products, whereas 12 were volunteers who had not taken part in a panel before but received theoretical training in sensory analysis before the evaluation. Participants were asked not to eat, drink, or smoke $2 \mathrm{~h}$ before the panel, with the exception of drinking water. We tallied the responses of the assessors of the flavor of the pita bread and calculated the averages and standard deviations. The 25 assessors' responses for the replicates of each sample were analyzed by a one-way ANOVA statistical test.

\section{Statistical Analysis}

Statistical analysis of data was performed using the software InfoStat version 2008 (https://www.infostat .com.ar/index.php?mod=page\&id=15). The differences between the groups were analyzed with one-way ANOVA followed by the Tukey HSD post-hoc test for multiple comparison. Results are expressed as mean values $\pm \mathrm{SE}$ means. The chosen significance level was $P \leq 0.01$.

\section{RESULTS AND DISCUSSION}

\section{Qualitative and Quantitative Evaluation of Antifungal Activity of Fermented Whey}

The leading cause of economic losses in bakery products is fungal contamination. Among bread contaminants, the most common responsible for fungal growth are Penicillium strains and molds derived from Aspergillus, Rhizopus, Eurotium, and Monilia genera (Saranraj and Geetha, 2012). An evaluation of pH with and without fermentation of whey by $4 \mathrm{~L}$. plantarum strains is shown in Table 1. We observed a decrease in $\mathrm{pH}$ of fermented whey compared with the unfermented product. The decrement in $\mathrm{pH}$ value from 5.9 to 5.5 (no fermentation and control whey, respectively) was due to the starter cultures used (Hill et al., 2017).

Table 1. pH measurement of whey with and without fermentation by 4 Lactobacillus plantarum strains (value $\pm \mathrm{SD}$ )

\begin{tabular}{lc}
\hline Treatment & $\mathrm{pH}$ \\
\hline Whey without fermentation & $5.9 \pm 0.01$ \\
After fermentation & $5.51 \pm 0.10$ \\
Whey control & \\
Whey fermented by L. plantarum CECT 220 & $3.50 \pm 0.04$ \\
Whey fermented by L. plantarum CECT 221 & $3.67 \pm 0.01$ \\
Whey fermented by L. plantarum CECT 223 & $3.45 \pm 0.01$ \\
Whey fermented by L. plantarum CECT 748 & $4.69 \pm 0.05$ \\
\hline
\end{tabular}

${ }^{1}$ The fermentation process of whey control does not include lactic acid bacteria.

Journal of Dairy Science Vol. 103 No. 7, 2020
The qualitative antifungal activity of sweet fermented whey against the tested fungi is detailed in Table 2 . Sweet whey fermented by L. plantarum 220, L. plantarum 221, and L. plantarum 223 had greater antifungal activity than sweet whey fermented by $L$. plantarum 748. The diameters of the inhibition zones toward the pathogenic strains were 9.0 and $10.0 \mathrm{~mm}$.

The antifungal activity of LSW in liquid medium against the tested fungi allowed us to determine MIC and MFC. The MIC and MFC values of goat whey fermented by strains of L. plantarum at $72 \mathrm{~h}$ of fermentation time are detailed in Table 2. The MFC ranged from 62.5 to $78.1 \mathrm{~g} / \mathrm{L}$ for whey fermented by $L$. plantarum CECT 220, 221, and 223, and was $250 \mathrm{~g} / \mathrm{L}$ for whey fermented by L. plantarum CECT 748 . The MIC ranged from 3.9 to $39.0 \mathrm{~g} / \mathrm{L}$ for the 2 tested fungi. The lowest MIC $(3.9 \mathrm{~g} / \mathrm{L})$ was found for L. plantarum 223 against $P$. expansum.

Our results showed that antifungal activity is correlated with the L. plantarum strain used in fermentation. Among different strains of LAB, L. plantarum can ferment a broad range of food products. In addition, it can be used as a starter culture in fermentation, prolonging the shelf life and safety of these products (Behera et al., 2018). Russo et al. (2016) screened 88 L. plantarum strains isolated from various matrices for their antifungal activity against 7 common contaminants of cereal and showed that L. plantarum can inhibit mycotoxigenic fungi, including $P$. expansum. This evidence, also reported by Tulini et al. (2016), demonstrated the antifungal activity of various strains of $815 \mathrm{LAB}$ isolated by 156 different dairy products. Lactobacillus plantarum FT723 demonstrated a satisfactory activity against $P$. expansum in a modified MRS agar and fermented milk model.

Furthermore, Juodeikiene et al. (2018) studied the ability of LAB metabolites derived from whey to add value to this by-product. The results confirmed that metabolites of LAB exhibited strong activity against mycotoxigenic fungi. Lactic acid bacteria are able to restrict the growth of fungi; consequently, this reduction in formation of toxins helps prevent food loss (Lowe and Arendt, 2004; Schillinger and Villarreal, 2010).

\section{Artificial Contamination and Natural Contamination of Pita Bread}

In recent years, interest in food biopreservation has increased. We used the mycotoxigenic strains $P$. expansum and P. brevicompactum to study shelf-life extension in pita bread. We included an experiment without fungal inoculation to test natural contamination by fungal spores in the environment. Table 3 shows the results of the different experiments. In the positive control 
(pita bread prepared without additives), growth of $P$. expansum and $P$. brevicompactum was visible on the surface of pita bread beginning on d 2, whereas in the negative control (pita bread prepared with additives), visible fungal growth began on d 6 .

We further extended the shelf life of pita bread by adding either freeze-dried or liquid whey that had been fermented using strains of L. plantarum. In this case, fungal growth of $P$. brevicompactum in pita bread prepared with $1 \%$ freeze-dried whey was observed on $\mathrm{d} 3$ of storage, whereas fungal growth was first observed between $\mathrm{d} 9$ and 10 (resulting in a total shelf life of 8 to $9 \mathrm{~d}$ ) in pita bread in which liquid fermented whey replaced the water in the dough. Similar results were observed for P. expansum, with the only difference being that fungal growth on pita bread prepared with $1 \%$ freeze-dried whey began at d 4 . Thus, using whey fermented with $L$. plantarum in pita bread dough, we were able to increase shelf life by 1 to $2 \mathrm{~d}$ (using freeze-dried whey) and by 7 to $8 \mathrm{~d}$ (using liquid fermented whey).

In the experiment to assess natural contamination of pita bread, we observed fungal growth on d 5 for the positive control and on d 6 for the negative control. A notable improvement in the shelf life of pita bread was achieved by adding fermented whey to the pita bread dough. In dough with freeze-dried whey, visible fungal growth was observed on $\mathrm{d} 7$ and 8 , whereas in dough prepared by replacing water with LSW, slight fungal growth was observed on d 19 for treatments 5 and 6 and on d 20 for treatment 4 .

Photographs of pita bread inoculated with $P$. brevicompactum and $P$. expansum (after $10 \mathrm{~d}$ ) and pita bread subjected to natural contamination (on d 20) are shown in Figure 1.

The results obtained in this work were in accordance with Gerez et al. (2009), who evaluated the ability of LAB to inhibit Aspergillus, Fusarium, and Penicillium in bread preparation. Using LAB in bread preparation, the authors reported an increase in the shelf life of 5 d compared with bread without LAB. Further, the addition of LAB in bread preparation made it possible to reduce calcium propionate (a synthetic preservative normally used in the preparation) by $50 \%$. These results agree with a recent study carried out by Le Lay et al. (2016). In the latter work, the addition of different LAB delayed fungal growth after LAB were incorporated during preparation of milk bread rolls. The ability of $L$. plantarum to produce antifungal compounds during sourdough fermentation have been reported by Dal Bello et al. (2007). Addition of LAB to bread could slow fungal growth compared with the use of chemical additives.

In research conducted by Rehman et al. (2007), LAB (Lactobacillus delbrueckii ssp. bulgaricus) were added 
Table 3. Shelf life (d; means \pm SD) of pita bread contaminated with Penicillium expansum, Penicillium brevicompactum, and natural contamination evaluated through visual observation ${ }^{1}$

\begin{tabular}{|c|c|c|c|}
\hline \multirow[b]{2}{*}{ Treatment $^{2}$} & \multicolumn{3}{|c|}{ Contamination } \\
\hline & P. expansum & P. brevicompactum & Natural \\
\hline Positive control & $2.4 \pm 0.7^{\mathrm{a}}$ & $2.1 \pm 0.3^{\mathrm{a}}$ & $5.3 \pm 0.5^{\mathrm{a}}$ \\
\hline Negative control & $6.1 \pm 0.8^{\mathrm{c}}$ & $6.2 \pm 0.8^{\mathrm{b}}$ & $6.3 \pm 0.5^{\mathrm{ab}}$ \\
\hline Treatment 1 & $3.9 \pm 0.8^{\mathrm{b}}$ & $2.7 \pm 0.5^{\mathrm{a}}$ & $7.8 \pm 0.4^{\mathrm{b}}$ \\
\hline Treatment 2 & $4.0 \pm 0.9^{\mathrm{b}}$ & $2.7 \pm 0.6^{\mathrm{a}}$ & $6.8 \pm 0.7^{\mathrm{ab}}$ \\
\hline Treatment 3 & $4.2 \pm 0.8^{\mathrm{b}}$ & $2.9 \pm 0.3^{\mathrm{a}}$ & $7.5 \pm 0.5^{\mathrm{b}}$ \\
\hline Treatment 4 & $9.7 \pm 0.6^{\mathrm{d}}$ & $9.7 \pm 0.8^{\mathrm{c}}$ & $19.8 \pm 0.4^{\mathrm{c}}$ \\
\hline Treatment 5 & $8.6 \pm 0.5^{\mathrm{d}}$ & $9.1 \pm 0.9^{c}$ & $18.8 \pm 0.7^{\mathrm{c}}$ \\
\hline Treatment 6 & $9.1 \pm 0.7^{\mathrm{d}}$ & $9.9 \pm 0.6^{\mathrm{c}}$ & $19.2 \pm 0.7^{\mathrm{c}}$ \\
\hline
\end{tabular}

alone and in combination with yeast (Saccharomyces cerevisiae) to evaluate effects on the shelf life of bread. Lactobacillus delbrueckii ssp. bulgaricus was most effective in inhibiting microbial spoilage and extending shelf life. Axel et al. (2015) tested LAB as a natural preservative in quinoa bread to inhibit spoilage. Results showed an increase of $4 \mathrm{~d}$ in the shelf life of the quinoa bread compared with the nonacidified control when sourdough fermented with Lactobacillus amylovorus DSM19280 was incorporated in the bread recipe. Coda et al. (2011) investigated the antifungal activity of Wickerhamomyces anomalus and sourdough LAB $(L$. plantarum) to extend the shelf life of wheat-flour bread. The bread manufactured with the combination of $L$. plantarum $1 \mathrm{~A} 7$ and $W$. anomalus LCF1695 showed the most volume and softness, and the fungal growth was delayed until at least $28 \mathrm{~d}$ of storage at room temperature under common storage conditions.

Moore et al. (2007) showed the effects of incorporation of sourdough fermented by $L$. plantarum FST 1.7 into a gluten-free bread to produce antifungal compounds. Results indicate that L. plantarum FST 1.7 can be used to produce gluten-free bread with increased quality and shelf life.

Ryan et al. (2008) investigated the sourdough fermented by the antifungal strains L. plantarum FST 1.7 or L. plantarum FST 1.9 for the ability to inhibit wheat bread spoilage caused by mycotoxigenic fungi. Possible synergistic effects of the combination of antifungal sourdoughs and calcium propionate in the bread formulation were evaluated. A strong synergistic effect was observed and the increase in shelf life was higher than that achieved using 3,000 ppm of calcium propionate alone. Saladino et al. (2016) tested 16 probiotic bacteria against 2 mycotoxigenic fungi, Aspergillus parasiti- cus and $P$. expansum, for their antifungal activity. The LAB strains that showed in vitro antifungal activity were used in bread fermentation with yeast to study fungal growth inhibition and aflatoxin reduction in processed bread previously inoculated with A. parasiticus. Results showed a reduction of aflatoxins ranging from 84.1 to $99.9 \%$ and an increased shelf life in bread of about 3 to 4 d. Gerez et al. (2010) tested 4 LAB strains for their capability to inhibit Penicillium spp. growth and lengthen shelf life with respect to breads prepared using only Saccharomyces cerevisiae (2-d shelf life). Lactobacillus plantarum CRL 778 provided the best biopreservation effect (a 5-d shelf life), which is as effective as $0.2 \%$ calcium propionate.

Recently, Gamba et al. (2016) optimized whey fermentation conditions with 3 types of kefir grains (IDCA, AGK1, and AGK2) to achieve better antifungal activity against Aspergillus spp. The inclusion of kefir fermented milk when preparing arepa (a Latin American cornmeal cake) provided greater resistance to fungal contamination and increased shelf life compared with the traditional arepa.

Luz et al. (2020) studied the antifungal effects of goat milk whey hydrolyzed by trypsin against 10 toxigenic fungi from the genus Penicillium. Fermented whey was added as an ingredient in bread preparation and inoculated with toxigenic fungi. Results showed an increase in the preservation period and a reduction in mycotoxin production.

Even though available studies report the antifungal activity of fermented whey, there are limited studies on the usage of fermented whey in baking. To the best of our knowledge, this is the first scientific report focused on the use of whey fermented by LAB used to improve the shelf life of pita bread. 
a)

\begin{tabular}{|l|l|l|l|}
\hline P. brevicompactum & L. plantarum 220 & L. plantarum 221 & L. plantarum 223 \\
\hline Positive control & \multicolumn{3}{|c|}{ Freeze-dried sweet whey } \\
\hline & & & \\
& & & \\
\hline & & & \\
\hline & & & \\
\hline & & & \\
\hline
\end{tabular}

b)

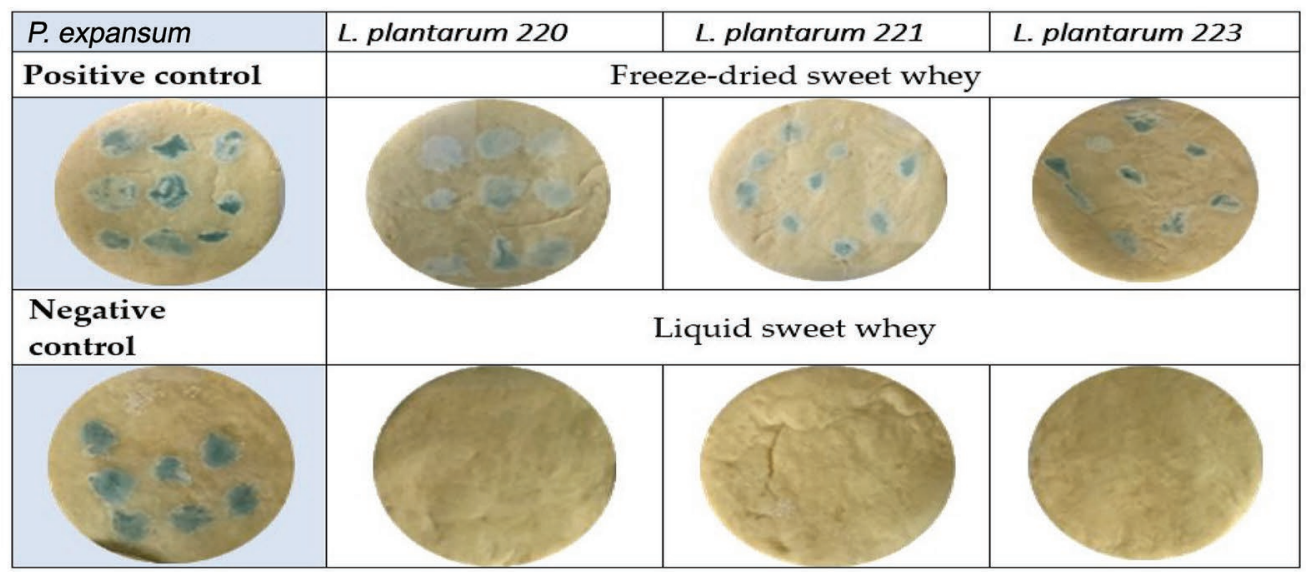

c)

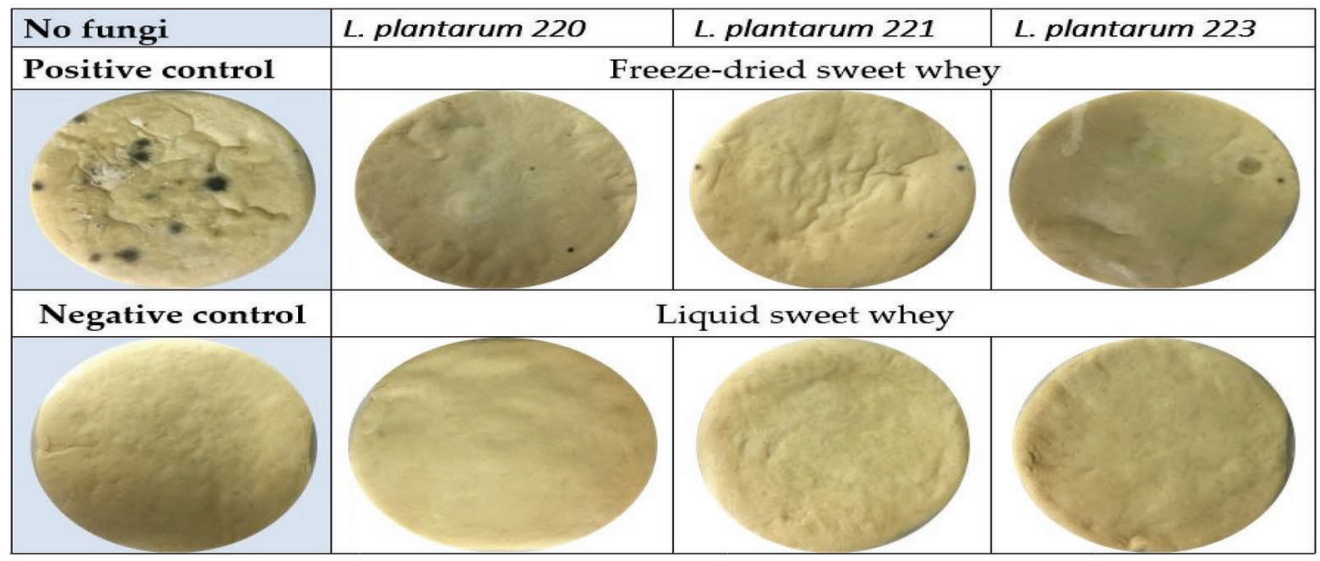

Figure 1. Images of pita bread inoculated with (a) Penicillium brevicompactum or (b) Penicillium expansum after $10 \mathrm{~d}$ of storage, and (c) pita bread without inoculation with fungi after $20 \mathrm{~d}$ of storage. Positive control was prepared without synthetic additives; negative control was prepared with calcium propionate; treatments 1,2, 3 were prepared with freeze-dried whey fermented with Lactobacillus plantarum; treatments 4, 5, 6 were prepared with liquid whey fermented with Lactobacillus plantarum replacing $100 \%$ of water in the dough.

\section{Antimicrobial Activity: Determination of Fungal Load}

At the end of the preservation period of pita bread $(10-20 \mathrm{~d})$, a microbiological study was performed to determine the fungal contamination present in each of the pita bread samples. First, the pH of pita bread after homogenization in the stomacher was measured; average values are shown in Table 4 . A decrease in $\mathrm{pH}$ values was observed in pita bread with the addition of fermented whey in the dough. A significant $(P \leq 0.01)$ 
Table 4. Average and relative standard deviations of $\mathrm{pH}$ of homogenized pita bread after preservation period $(10-20 \mathrm{~d})$

\begin{tabular}{lccc}
\hline Treatment $^{1}$ & $\begin{array}{c}\text { Penicillium } \\
\text { expansum }\end{array}$ & $\begin{array}{c}\text { Penicillium } \\
\text { brevicompactum }\end{array}$ & $\begin{array}{c}\text { Natural } \\
\text { contamination }\end{array}$ \\
\hline Positive control & $5.79 \pm 0.072^{\mathrm{gghi}}$ & $6.08 \pm 0.03^{\mathrm{ghi}}$ & $6.11 \pm 0.02^{\mathrm{i}}$ \\
Negative control & $5.82 \pm 0.130^{\mathrm{fghi}}$ & $5.94 \pm 0.02^{\mathrm{hi}}$ & $5.71 \pm 0.22^{\mathrm{efg}}$ \\
Treatment 1 & $5.36 \pm 0.015^{\mathrm{cd}}$ & $5.59 \pm 0.01^{\mathrm{def}}$ & $5.51 \pm 0.14^{\mathrm{def}}$ \\
Treatment 2 & $5.57 \pm 0.066^{\mathrm{def}}$ & $5.78 \pm 0.10^{\mathrm{fgh}}$ & $5.64 \pm 0.28^{\mathrm{defg}}$ \\
Treatment 3 & $5.42 \pm 0.010^{\mathrm{de}}$ & $5.55 \pm 0.05^{\mathrm{def}}$ & $5.54 \pm 0.06^{\mathrm{def}}$ \\
Treatment 4 & $4.82 \pm 0.056^{\mathrm{ab}}$ & $4.86 \pm 0.01^{\mathrm{ab}}$ & $4.95 \pm 0.02^{\mathrm{ab}}$ \\
Treatment 5 & $4.94 \pm 0.038^{\mathrm{ab}}$ & $5.03 \pm 0.04^{\mathrm{b}}$ & $5.08 \pm 0.01^{\mathrm{bc}}$ \\
Treatment 6 & $4.63 \pm 0.026^{\mathrm{a}}$ & $4.64 \pm 0.02^{\mathrm{a}}$ & $4.76 \pm 0.03^{\mathrm{ab}}$ \\
\hline
\end{tabular}

${ }^{\mathrm{a}-\mathrm{i}}$ Different letters show significant differences $(P \leq 0.01)$ among treatments.

${ }^{1}$ Positive control $=$ dough without synthetic additives; negative control $=$ dough with calcium propionate; treatments $1,2,3=$ dough prepared with freeze-dried fermented whey; treatments $4,5,6=$ dough with $100 \%$ of water replaced with liquid whey fermented with Lactobacillus plantarum.

percentage of $\mathrm{pH}$ reduction was observed in pita bread prepared with the replacement of $100 \%$ water with fermented whey during preparation. The $\mathrm{pH}$ decreased to between 4.63 and 5.08 in treatments 4,5 , and 6 . A decrease in $\mathrm{pH}$ values of pita bread dough during the fermentation period using $L$. plantarum strain was also observed by Gezginc and Kara (2019). The antifungal effect is likely related to the nature of the organic acid produced during fermentation (such as lactic or acetic acid) or the low $\mathrm{pH}$ reached after fermentation, or both. The decrease in $\mathrm{pH}$ is influenced by the release of weak organic acids such as lactic acid, which is principally dependent on the undissociated molecule, the percentage of which increases with decreasing $\mathrm{pH}$ (Smith et al., 2004). Luz et al. (2018) reported that secondary metabolites produced during the fermentation process of whey by LAB could create an unfavorably acidic environment for the fungal growth of pathogenic microorganisms and that organic acids were the main responsible agent for antimicrobial effect.

In this data reported, the antifungal effect is fairly well correlated with bread $\mathrm{pH}$ and could confirm our hypothesis. However, the replacement of all water in the bread recipe with fermented whey to make pita bread may also have influenced water activity. This potential reduction of water activity could be responsible for the effect of the shelf life increase (Sandulachi, 2012). Although reduced $\mathrm{pH}$ and a decrease in water activity can play an important role in extending shelf life, we demonstrated strong antifungal activity of whey fermented by Lactobacillus strains in both liquid (MIC and MFC) and solid assays. All these factors could explain the final results, indicating an increase in the shelf life of pita bread through additive or synergistic effects.

We observed significant reductions in fungal growth in pita breads prepared using fermented whey (Table 5). Adding 1\% freeze-dried fermented whey in pita bread resulted in reductions in fungal growth to counts between 4.00 and $2.15 \mathrm{log} \mathrm{cfu} / \mathrm{g}$, whereas using fermented LSW to replace water in the dough resulted in reductions to counts between 2.17 and $0.23 \mathrm{log} \mathrm{cfu} / \mathrm{g}$.

In the current work, we propose a novel possibility to prevent or delay food deterioration. Today, the use of

Table 5. Antimicrobial activity (log cfu/g; means \pm SD) and percent reduction of fungal growth evaluated in pita bread after preservation period $(10-20 \mathrm{~d})$

\begin{tabular}{|c|c|c|c|c|c|c|}
\hline \multirow[b]{2}{*}{ Treatment $^{1}$} & \multicolumn{2}{|c|}{ Penicillium expansum } & \multicolumn{2}{|c|}{ Penicillium brevicompactum } & \multicolumn{2}{|c|}{ Without fungi } \\
\hline & Log $\mathrm{cfu} / \mathrm{g}$ & $\%$ reduction & Log $\mathrm{cfu} / \mathrm{g}$ & $\%$ reduction & $\log \mathrm{cfu} / \mathrm{g}$ & $\%$ reduction \\
\hline Positive control & $4.52 \pm 0.44^{\mathrm{a}}$ & - & $3.30 \pm 0.07^{\mathrm{ab}}$ & - & $3.77 \pm 0.09^{\mathrm{a}}$ & - \\
\hline Negative control & $4.37 \pm 0.15^{\mathrm{ab}}$ & $54 \pm 16$ & $2.78 \pm 0.44^{\mathrm{a}}$ & $74 \pm 22$ & $3.11 \pm 0.13^{\mathrm{ab}}$ & $78 \pm 7$ \\
\hline Treatment 1 & $4.00 \pm 0.16^{\mathrm{ab}}$ & $81 \pm 6$ & $2.34 \pm 0.42^{\mathrm{ab}}$ & $92 \pm 5$ & $2.91 \pm 0.05^{\mathrm{bc}}$ & $87 \pm 2$ \\
\hline Treatment 2 & $4.00 \pm 0.27^{\mathrm{ab}}$ & $77 \pm 18$ & $2.33 \pm 0.27^{\mathrm{ab}}$ & $89 \pm 7$ & $3.00 \pm 0.12^{\mathrm{ab}}$ & $83 \pm 5$ \\
\hline Treatment 3 & $3.67 \pm 0.25^{\mathrm{ab}}$ & $90 \pm 5$ & $2.15 \pm 0.12^{\mathrm{b}}$ & $94 \pm 2$ & $2.96 \pm 0.13^{\mathrm{b}}$ & $84 \pm 5$ \\
\hline Treatment 4 & $0.57 \pm 0.90^{\mathrm{c}}$ & $100 \pm 0$ & $0.39 \pm 0.43^{\mathrm{c}}$ & $100 \pm 0$ & $1.20 \pm 0.90^{\mathrm{d}}$ & $99 \pm 1$ \\
\hline Treatment 5 & $0.31 \pm 0.57^{\mathrm{c}}$ & $100 \pm 0$ & $0.86 \pm 1.01^{\mathrm{c}}$ & $98 \pm 3$ & $2.17 \pm 0.50^{c}$ & $96 \pm 3$ \\
\hline Treatment 6 & $0.73 \pm 0.66^{\mathrm{c}}$ & $100 \pm 0$ & $0.23 \pm 0.36^{\mathrm{c}}$ & $100 \pm 0$ & $0.56 \pm 0.53^{\mathrm{d}}$ & $100 \pm 0$ \\
\hline
\end{tabular}

${ }^{\mathrm{a}-\mathrm{d}}$ Different letters show significant difference $(P \leq 0.01)$ among treatments.

${ }^{1}$ Positive control $=$ dough without synthetic additives; negative control $=$ dough with calcium propionate; treatments $1,2,3=$ dough prepared with freeze-dried fermented whey; treatments $4,5,6=$ dough with $100 \%$ of water replaced with liquid whey fermented with Lactobacillus plantarum. 
chemical additives is widespread worldwide and several food additives are used to increase shelf life (EC No. 1333/2008; European Commission, 2008). Propionic or propanoic acid is added to food, particularly in bakery products, to reduce molds and fungal contamination (Carocho et al., 2014). Consumers today want lessprocessed foods and natural compounds used in food preservation. Therefore, there is growing interest in using metabolites derived from fermentation to reduce fungal growth as an alternative to chemical preservation (Leyva Salas et al., 2017). Currently, bioconservation by $\mathrm{LAB}$ is the main alternative to replace synthetic preservatives in food. The LAB have been widely investigated because of their ability to induce the production of antifungal metabolites, their role in fermented foods, and their "generally regarded as safe" (GRAS) status (Crowley et al., 2013).

\section{Sensory Quality}

We evaluated the sensory profile (texture and flavor) of the different types of pita bread. The texture attributes and most appearance attributes were not significantly different between treatments. The analysis of the mean flavor scores given by the assessors revealed no significant difference among the treatments. Results demonstrated the highest average score for the positive control $(7.1 \pm 1.0$, corresponding to slightly like), followed by the negative control $(6.6 \pm 0.9$, neither like or dislike), treatments 1,2 , and $3(6.5 \pm 0.9$, neither like or dislike), and finally, treatments 4,5 , and 6 (6.3 \pm 1.1 , neither like or dislike). Differences between pita breads of different types could not be perceived by the untrained panel. These results could be due to inconsistencies between assessors, which can be attributed to different use of the scales.

\section{CONCLUSIONS}

Whey represents a major by-product of the dairy industry. Whey fermented by strains of LAB inhibited fungal growth of species of Penicillium. Our results suggest the possibility of reusing fermented whey in the food industry. By adding fermented whey to pita bread dough, we extended the shelf life to $19 \mathrm{~d}$ under natural contamination conditions, an increase of $14 \mathrm{~d}$ compared with the positive control. These results support our hypothesis of incorporating whey as a functional component and a natural antimicrobial compound to control fungal contaminants and extend the shelf life of foods. Further research is warranted to expand our knowledge on the effectiveness of whey fermented by $\mathrm{LAB}$, which could reduce the use of food additives and lead to future applications in food model systems.

\section{ACKNOWLEDGMENTS}

The research was supported by the Spanish Ministry of Economy and Competitiveness (AGL2016-77610R), the project Prometeo (2018/126) of Generalitat Valenciana, and by pre $\mathrm{PhD}$ program of University of Valencia (Atracció de Talent). Authors also acknowledge the technical support of Vittoria Lanni. The authors declare no conflict of interest.

\section{REFERENCES}

Axel, C., B. Röcker, B. Brosnan, E. Zannini, A. Furey, A. Coffey, and E. K. Arendt. 2015. Application of Lactobacillus amylovorus DSM19280 in gluten-free sourdough bread to improve the microbial shelf-life. Food Microbiol. 47:36-44. https://doi.org/10.1016/ j.fm.2014.10.005.

Axel, C., E. Zannini, and E. K. Arendt. 2017. Mold spoilage of bread and its biopreservation: A review of current strategies for bread shelf life extension. Crit. Rev. Food Sci. Nutr. 57:3528-3542. https: //doi.org/10.1080/10408398.2016.1147417.

Bacenetti, J., L. Bava, A. Schievano, and M. Zucali. 2018. Whey protein concentrate (WPC) production: Environmental impact assessment. J. Food Eng. 224:139-147. https://doi.org/10.1016/j .jfoodeng.2017.12.018.

Behera, S. S., R. C. Ray, and N. Zdolec. 2018. Lactobacillus plantarum with functional properties: an approach to increase safety and shelf-life of fermented foods. BioMed Res. Int. 2018:9361614. https: //doi.org/10.1155/2018/9361614.

Carocho, M., M. F. Barreiro, P. Morales, and I. C. Ferreira. 2014. Adding molecules to food, pros and cons: A review on synthetic and natural food additives. Compr. Rev. Food Sci. Food Saf. 13:377399. https://doi.org/10.1111/1541-4337.12065.

CLAL. 2016. Processing on data FAS-USD. Accessed Sep. 1, 2019. https://www.clal.it/mini_index.php?section=produzione_cheese $\_$siero\&mode $=\% 20 \mathrm{mi}$ ni\&h $=450 \& \mathrm{w}=950$.

Coda, R., A. Cassone, C. G. Rizzello, L. Nionelli, G. Cardinali, and M. Gobbetti. 2011. Antifungal activity of Wickerhamomyces anomalus and Lactobacillus plantarum during sourdough fermentation: Identification of novel compounds and long-term effect during storage of wheat bread. Appl. Environ. Microbiol. 77:3484-3492. https:// doi.org/10.1128/AEM.02669-10.

Crowley, S., J. Mahony, and D. van Sinderen. 2013. Current perspectives on antifungal lactic acid bacteria as natural bio-preservatives. Trends Food Sci. 33:93-109.

Dal Bello, F., C. I. Clarke, L. A. M. Ryan, H. Ulmer, T. J. Schober, K. Ström, J. Sjögren, D. van Sinderen, J. Schnürer, and E. K. Arendt. 2007. Improvement of the quality and shelf life of wheat bread by fermentation with the antifungal strain Lactobacillus plantarum FST 1.7. J. Cereal Sci. 45:309-318. https://doi.org/10 $.1016 / j . j c s .2006 .09 .004$.

Dullius, A., M. I. Goettert, and C. F. V. de Souza. 2018. Whey protein hydrolysates as a source of bioactive peptides for functional foods-Biotechnological facilitation of industrial scale-up. J. Funct. Foods 42:58-74. https://doi.org/10.1016/j.jff.2017.12.063.

EFSA (European Food Science Association). 2016. Panel on Food Additives and Nutrient Sources added to Food (ANS). Safety of the extension of use of sodium propionate (E 281) as a food additive. EFSA J. 14:e04546.

European Commission. 2008. Regulation (EC) No 1333/2008 of the European Parliament and of the Council of 16 December 2008 on food additives. Off J. Eur. Union 354:16-33.

Gamba, R. R., C. A. Caro, O. L. Martínez, A. F. Moretti, L. Giannuzzi, G. L. De Antoni, and A. L. Peláez. 2016. Antifungal effect of kefir fermented milk and shelf life improvement of corn arepas. Int. J. Food Microbiol. 235:85-92. 
Ganju, S., and P. R. Gogate. 2017. A review on approaches for efficient recovery of whey proteins from dairy industry effluents. J. Food Eng. 215:84-96. https://doi.org/10.1016/j.jfoodeng.2017.07.021.

Gerez, C. L., M. I. Torino, M. D. Obregozo, and G. F. de Valdez. 2010. A ready-to-use antifungal starter culture improves the shelf life of packaged bread. J. Food Prot. 73:758-762.

Gerez, C. L., M. I. Torino, G. Rollán, and G. Font de Valdez. 2009. Prevention of bread mould spoilage by using lactic acid bacteria with antifungal properties. Food Contr. 20:144-148. https://doi .org/10.1016/j.foodcont.2008.03.005.

Gezginc, Y., and U. Kara. 2019. The effect of exopolysaccharide producing Lactobacillus plantarum strain addition on sourdough and wheat bread quality. Qual. Assur. Saf. Crop. 11:95-106. https:// doi.org/10.3920/QAS2018.1361.

Gustavsson, J., C. Cederberg, U. Sonesson, R. Van Otterdijk, and A. Meybeck. 2011. Global food losses and food waste. Pages 1-38. FAO, Rome, Italy. https://www.madr.ro/docs/ind-alimentara/ risipa_alimentara/presentation_food_waste.pdf.

Hill, D., I. Sugrue, E. Arendt, C. Hill, C. Stanton, and R. P. Ross. 2017. Recent advances in microbial fermentation for dairy and health. F1000Res 6:751. https://doi.org/10.12688/f1000research .10896.1.

Jideani, V. A., and K. Vogt. 2016. Antimicrobial packaging for extending the shelf life of bread-A review. Crit. Rev. Food Sci. Nutr. $56: 1313-1324$

Juodeikiene, G., D. Zadeike, I. Vidziunaite, E. Bartkiene, V. Bartkevics, and I. Pugajeva. 2018. Effect of heating method on the microbial levels and acrylamide in corn grits and subsequent use as functional ingredient for bread making. Food Bioprod. Process. 112:22-30. https://doi.org/10.1016/j.fbp.2018.08.007.

Kelly, S., L. H. Grimm, C. Bendig, D. C. Hempel, and R. Krull. 2006. Effects of fluid dynamic induced shear stress on fungal growth and morphology. Process Biochem. 41:2113-2117. https://doi.org/10 1016/j.procbio.2006.06.007.

Le Lay, C., J. Mounier, V. Vasseur, A. Weill, G. Le Blay, G. Barbier, and E. Coton. 2016. In vitro and in situ screening of lactic acid bacteria and propionibacteria antifungal activities against bakery product spoilage molds. Food Control 60:247-255. https://doi .org/10.1016/j.foodcont.2015.07.034

Leroy, F., and L. De Vuyst. 2004. Lactic acid bacteria as functional starter cultures for the food fermentation industry. Trends Food Sci. Technol. 15:67-78. https://doi.org/10.1016/j.tifs.2003.09.004.

Leyva Salas, M., J. Mounier, F. Valence, M. Coton, A. Thierry, and E. Coton. 2017. Antifungal microbial agents for food biopreservation-A review. Microorganisms 5:37. https://doi.org/10.3390/ microorganisms5030037.

Lowe, D. P., and E. K. Arendt. 2004. The use and effects of lactic acid bacteria in malting and brewing with their relationships to antifungal activity, mycotoxins and gushing: A review. J. Inst. Brewing 110:163-180. https://doi.org/10.1002/j.2050-0416.2004 .tb00199.x.

Luz, C., L. Izzo, G. Graziani, A. Gaspari, A. Ritieni, J. Mañes, and G. Meca. 2018. Evaluation of biological and antimicrobial properties of freeze-dried whey fermented by different strains of Lactobacillus plantarum. Food Funct. 9:3688-3697. https://doi.org/10.1039/ C8FO00535D

Luz, C., L. Izzo, A. Ritieni, J. Mañes, and G. Meca. 2020. Antifungal and antimycotoxigenic activity of hydrolyzed goat whey on Penicillium spp: An application as biopreservation agent in pita bread. LWT 118:108717. https://doi.org/10.1016/j.lwt.2019.108717.

Mondal, A., and A. K. Datta. 2008. Bread baking-A review. J. Food Eng. 86:465-474. https://doi.org/10.1016/j.jfoodeng.2007.11.014.

Puškárová, A., M. Bučková, L. Kraková, D. Pangallo, and K. Kozics. 2017. The antibacterial and antifungal activity of six essential oils and their cyto/genotoxicity to human HEL 12469 cells. Sci. Rep. 7:8211. https://doi.org/10.1038/s41598-017-08673-9.

Raveschot, C., B. Cudennec, F. Coutte, C. Flahaut, M. Fremont, D. Drider, and P. Dhulster. 2018. Production of bioactive peptides by
Lactobacillus species: From gene to application. Front. Microbiol. 9:2354. https://doi.org/10.3389/fmicb.2018.02354.

ur-Rehman, S., H. Nawaz, S. Hussain, M. Mushtaq Ahmad, M. Anjum Murtaza, and M. Saeed Ahmad. . 2007. Effect of sourdough bacteria on the quality and shelf life of bread. Pak. J. Nutr. 6:562-565. https://doi.org/10.3923/pjn.2007.562.565.

Ribes, S., A. Fuentes, P. Talens, and J. M. Barat. 2018. Prevention of fungal spoilage in food products using natural compounds: A review. Crit. Rev. Food Sci. Nutr. 58:2002-2016.

Roth-Walter, F., M. C. Berin, P. Arnaboldi, C. R. Escalante, S. Dahan, J. Rauch, E. Jensen-Jarolim, and L. Mayer .2008. Pasteurization of milk proteins promotes allergic sensitization by enhancing uptake through Peyer's patches. Allergy 63:882-890. https://doi .org/10.1111/j.1398-9995.2008.01673.x.

Russo, P., M. L. V. de Chiara, V. Capozzi, M. P. Arena, M. L. Amodio, A. Rascón, M. T. Dueñas, P. López, and G. Spano. 2016. Lactobacillus plantarum strains for multifunctional oat-based foods. Lebensm. Wiss. Technol. 68:288-294. https://doi.org/10.1016/j .lwt.2015.12.040.

Ryan, L. A. M., F. Dal Bello, and E. K. Arendt. 2008. The use of sourdough fermented by antifungal LAB to reduce the amount of calcium propionate in bread. Int. J. Food Microbiol. 125:274-278.

Ryan, L. A., E. Zannini, F. Dal Bello, A. Pawlowska, P. Koehler, and E. K. Arendt. 2011. Lactobacillus amylovorus DSM 19280 as a novel food-grade antifungal agent for bakery products. Int. J. Food Microbiol. 146:276-283. https://doi.org/10.1016/j.ijfoodmicro .2011.02.036.

Saladino, F., C. Luz, L. Manyes, M. Fernández-Franzón, and G. Meca. 2016. In vitro antifungal activity of lactic acid bacteria against mycotoxigenic fungi and their application in loaf bread shelf life improvement. Food Control 67:273-277. https://doi.org/10.1016/ j.foodcont.2016.03.012

Samapundo, S., F. Devlieghere, A. Vroman, and M. Eeckhout. 2017. Antifungal activity of fermentates and their potential to replace propionate in bread. LWT 76:101-107. https://doi.org/10.1016/ j.lwt.2016.10.043.

Sandulachi, E. 2012. Water Activity Concept and its Role in Food Preservation. Technical University of Moldova. http://www.utm .md/meridian/2012/MI_4__2012/8_Art_Sandulachi_E_Water. pdf.

Saranraj, P., and M. Geetha. 2012. Microbial spoilage of bakery products and its control by preservatives. Int. J. Pharm. Biol. Sci Arch. 3:38-48.

Schillinger, U., and J. V. Villarreal. 2010. Inhibition of Penicillium nordicum in MRS medium by lactic acid bacteria isolated from foods. Food Control 21:107-111. https://doi.org/10.1016/j.foodcont.2008 .11.010.

Smith, J. P., D. P. Daifas, W. El-Khoury, J. Koukoutsis, and A. ElKhoury. 2004. Shelf life and safety concerns of bakery products-A review. Crit. Rev. Food Sci. Nutr. 44:19-55. https://doi.org/10 $.1080 / 10408690490263774$

Trindade, M. B., B. C. V. Soares, H. Scudino, J. T. Guimarães, E. A. Esmerino, M. Q. Freitas, T. C. Pimentel, M. C. Silva, S. L. Q. Souza, R. B. Almada, and A. G. Cruz. 2019. Cheese whey exploitation in Brazil: A questionnaire survey. Food Sci. Technol. 39:788-791. https://doi.org/10.1590/fst.07419.

Tulini, F. L., N. Hymery, T. Haertlé, G. Le Blay, and E. C. De Martinis. 2016. Screening for antimicrobial and proteolytic activities of lactic acid bacteria isolated from cow, buffalo and goat milk and cheeses marketed in the southeast region of Brazil. J. Dairy Res. 83:115-124. https://doi.org/10.1017/S0022029915000606.

\section{ORCIDS}

L. Izzo @ https://orcid.org/0000-0002-8365-9032

A. Ritieni @ https://orcid.org/0000-0003-0314-8839 